\title{
Embryo Rescue in Horticultural Crops
}

\author{
Poonam Kumari $^{1 *}$, Thaneshwari ${ }^{1}$ and Rahul $^{2}$ \\ ${ }^{1}$ Department of Horticulture, School of Agriculture, Lovely Professional University, \\ Jalandhar-144411, India \\ ${ }^{2}$ Department of Biotechnology, Maharishi Markandeshwar University, Mullana, Ambala, \\ Haryana, 133203, India \\ *Corresponding author
}

\section{A B S T R A C T}

\begin{tabular}{|l|}
\hline Ke y w o r d s \\
$\begin{array}{l}\text { Embryo rescue, } \\
\text { horticultural crops, post- } \\
\text { zygotic barriers, tissue } \\
\text { culture, interspecific } \\
\text { hybrids }\end{array}$ \\
\hline Article Info \\
\hline $\begin{array}{l}\text { Accepted: } \\
\text { 22 May } 2018 \\
\text { Available Online: } \\
\text { 10 June } 2018\end{array}$ \\
\hline
\end{tabular}

\section{Introduction}

Improvement of cultivated plants depends on introducing natural variability through traditional and biotechnological breeding techniques. Intervarietal and interspecific crosses, followed by selection, have accounted for the improvement in quality and yield potential of practically all major crops (Raghavan, 1976). The production of interspecific hybrids is useful for the transfer of desirable genes from wild to cultivated species. In many cases, wide crosses between species are difficult to produce because of many factors like prezygotic and postzygotic. Post-zygotic barriers such as endosperm abortion and embryo degeneration leading to low fertility have been overcome through the use of embryo culture and several hybrids have been developed in horticultural crops.

Embryo rescue involves isolating and growing an immature or mature zygotic embryo under sterile conditions on an aseptic nutrient medium with the goal of obtaining a viable plant. The culture of immature embryos is used to rescue embryos that would normally abort or that would not undergo the progressive sequence of ontogeny. This process is difficult due to the tedious dissection necessary and the complex nutrient medium requirements. The success of this technique depends on isolating the embryo without injury, formulating a suitable nutrient 
medium, and inducing continued embryogenic growth and seedling formation (Monnier, 1984 \& Raghavan, 1980).

The culture of mature embryos from ripened seeds is used to eliminate seed germination inhibitors or to shorten the breeding cycle if, for example, dormancy is a problem. This culture is easy and only requires a simple nutrient medium with agar, sugar, and minerals. Since the early 1940s, embryo culture has been used increasingly to understand the physical and nutritional requirements for embryonic development, bypass seed dormancy, shorten the breeding cycle, test seed viability, provide material for micropropagation and rescue immature hybrid embryos from incompatible crosses ( $\mathrm{Hu}$ and Wang, 1986).

Plant breeders usually rescue inherently weak, immature or hybrid embryos to prevent their degeneration. Successful production of plants from cultured embryos depends largely upon maturation stage and composition of the medium besides, of course, the genotype. Abortion of embryos at one or the other stage of development is a characteristic feature of distant hybridization. Hybrid embryo rescue is a popular approach for raising hybrids. Currently, embryo rescue holds great promise for not only effecting wide crosses but also for obtaining haploid plants, and for shortening breeding cycle in presence or absence of a protracted dormancy.

\section{Applications of Embryo Rescue Technique}

\section{Shortening of breeding cycles}

Embryo culture has also been used to shorten breeding cycles in various horticultural crops where effective germination was reduced from years to months by overcoming dormancy. The factors which cause dormancy are endogenous inhibitors, low temperatures, dry storage requirements, light requirements and embryo immaturity. Breeding cycle can be shortened by removing the embryos from the influences of these factors which localized in the seedcoat and endosperm, or both. Embryo culture has also been used to shorten breeding cycles in apple (Nickell, 1951), where effective germination was reduced from years to months by overcoming dormancy. Vernalization of isolated embryos can also reduce the breeding time. This technique had been found to increase germination percentage of mature seeds in early-ripening sweet cherry cultivars 'Silej-Delamarka' by 30 and 60 percent as compare to control (Fathi et al., 2002). Anderson and co-worker developed rapid generation cycling techniques which hasten the formulation of theoretical models for inbreeding depression or genetic load, heterosis, F1 hybrid development, and selfincompatibility genetics in chrysanthemum (Anderson et al., 1990). The breeding cycle of papaya could be shortened by embryo culture using embryos qualitatively improved by ethrel treatment, i.e., the period (generally 69 months) from pollination to seedling establishment could be shortened by approximately 3 months using these breeding techniques (Tamaki et al., 2011).

\section{Wide crosses}

Embryo rescue has also been used to overcome postzygotic barriers during self- and cross-incompatibility (Fassuliotus, 1977). The successful protocol for culture of embryos of lilium seeds without an endosperm and originating from interspecific crosses involving Lilium lankongens was developed (North and Wills, 1969). Interspecific hybrids were developed in pelargonium by applying embryo rescue methods (Bentvelsen et al., 1990). Embryo rescue and plant regeneration has been successfully demonstrated in cacti following interspecific crosses in the genus Hylocereus by Aroldo and Noemi (2010). 
Ovary culture has also been shown to be possible in the vine cacti Hylocereus and Selenicereus (Benega-Garcia et al., 2009). Different genomic combinations in intersection hybrids from crosses in primulas were developed through embryo rescue (Kato et al., 2001). Tom Eeckhaut et al., (2007) reported that Interspecific hybridization in rhododendron was possible using embryo rescue. Interspecific crossing barriers in tulips were overcame using embryo rescue by successful direct transfer of Tulipa kaufmanniana Regel germplasm into that of $T$. gesneriana L (Custers, 1995). In banana, commercially popular varieties are seedless owing to their triploid status. Interspecific hybrids between Musa acuminata and $M$. balbisiana were developed using embryo rescue techniques (Doreswamy and Sahijram, 1993; Chadha and Sahijram, 2000). Embryo rescue is also used to recover crosses between diploids and tetraploid species.

\section{Seedlessness}

Many seedless grape cultivars are stenospermocarpic i.e., they are characterized by cessation of embryo development after fertilization and failure of seed development. Cain et al., (1983) used embryo rescue technique for the first time in grapes and, subsequently, this technique was improved by other researchers (Aguero et al., 1995; Singh et al., 2011). Embryos have been rescued and grown into plants from stenospermocarpic seedless grapes, allowing growth of progeny resulting from the hybridization of seedless with seedless grapes (Spiegel-Roy, 1985). Role of embryo culture techniques in improvement of fruit quality in seedless lime was elucidated (Prasad et al., 1996).

\section{Production of haploids}

Haploidisation is a biotechnological method used to obtain plants with improved traits that are of use to humans. Embryo culture can be used for production of haploids or monoploids. A technique was to produce barley monoploids. Interspecific crosses are made with Hordeum bulbosum as the pollen parent, and the resulting hybrid embryos are cultured. But, these exhibit $H$. bulbosum chromosome elimination, resulting in monoploids of the female parent $H$. vulgare (Kasha and Kao, 1970). Haploid plants of lettuce were developed through embryo culture techniques (Zenkteler and Zenkteler, 2016). Doubled haploids of carnation (Dianthus caryophyllus L.) were obtained by pseudofertilized ovule culture (Sato et al., 2000)

\section{Resistance to biotic and abiotic stresses}

Table 1 depicts that some hybrids obtained through embryo rescue have recombined desirable genes like disease and pest resistance in various horticultural crops. Interspecific crosses were made between Chrysanthemum $\times$ grandiflorum and C. makinoi and Nakai using embryo rescue technique. Aphid and heat resistance was reported in MR1, MR2 and the BC1F1 hybrids of these crosses (Cheng et al., 2011). Interspecific hybrids were also developed between Lycopersicon esculentum $\mathrm{x}$ L. peruvianum using embryo rescue. Resistant genes were introgressed into cultivated tomato showing good resistance against PBNV (Peanut bud necrosis virus) and bearing big size, red color and desired shape tomato fruits (Sohrab et al., 2015)

\section{Rapid testing of seed viability}

Embryo culture has been very useful in determining seed viability. The use of this technique arose out of early findings that there was a good correlation between the growth of excised embryos of non-after-ripened peach seeds and germination of the after ripened seeds (Tukey and Carlson, 1945). Embryo 
culture allows the rapid testing of seed viability when seed dormancy can be circumvented.

\section{Germination}

Seed dormancy can be caused by numerous factors, including endogenous inhibitors, specific light-requirements, low temperature, dry-storage requirements and embryo immaturity. Seeds of many species exhibit orthodox dormancy which, is, inhibition of germination by presence of certain plant hormones in tissues surrounding the embryo within a seed. Embryo culture can be successfully used as a tool in an apricot (Burgos and Ledbetter, 1993) and sweet cherry (Balla and Brozik, 1993) breeding program to obtain higher percentages of seedling from planed hybridization or to overcome a lack of seed germination. An efficient protocol was developed for embryo rescue in two floribunda roses ('Arunima' and 'Shocking Blue'). The germination of immature embryos was achieved by manipulating the growth media, growth hormones and culture conditions (Mohapatra and Rout, 2005)

\section{Prevention of embryo abortion with early ripening stone fruits}

Early-ripening varieties of peach, cherry, apricot and plum produce sterile seeds which do not germinate under natural conditions and, eventually, decay in the soil. Seed sterility here may be due to incomplete embryodevelopment, so embryo culture helps in germination of such type of fruits.

\section{Embryos for propagation/ conservation/ germplasm exchange}

Embryos are excellent material for in vitro preservation and propagation. As per IPGRI, Rome, it is compulsory to exchange germplasm of coconut internationally using embryo cultures (otherwise, shipping of whole nuts is cumbersome besides requiring huge cargo-space on flights or ships). Identifying a safest method for international exchange of coconut germplasm that is free of known diseases is a pre-request for cryogenic storage. Coconut germplasm exchange is possible only as embryos or embryo containing endosperm plugs and raising of seedlings through in vitro embryo culture technique, which prevent the introduction of pests and diseases inadvertently (Assy-Bah et al., 1987). Utami et al., (2017) developed in vitro propagation protocol for endangered medicinal orchid (Dendrobium lasianthera) through mature seed culture.

\section{Factors Affecting the Success of Embryo Culture}

Before attempting to elucidate the application of embryo culture method, it is necessary to analyze briefly the factors influencing the embryo culture technique. Various factors which affect the success of embryo culture are described below:

\section{Genotypes}

Success of embryo culture varied from genotype to genotype. Vidhanaarachchi and co-worker studied the effect of different genotype of coconut on embryo culture response. Significant variation in in vitro germination was observed between the selected cultivars, San Ramon Tall (SNRT) (77.48 \%), Sri Lanka Red Dwarf (SLRD) (67.28\%), Sri Lanka Green Dwarf (PGD) (71.85\%) and King Coconut (RTB) (52.5\%) (Vidhanaarachchi et al., 2016). Lu and Bridgen, (1997) reported that percentages of embryo germination, and callus and shoot developments were significantly affected by the parental genotype in the interspecific crosses of Alstroemeria. 
Developmental stage of the embryo at isolation

The culture of very young embryos is very difficult. Despite considerable progress in the field of embryo culture, embryo rescuing seems to be difficult where embryo abortion occurs at a very early stage of development. To culture very young embryos successfully, the embryo of a particular species is implanted in the endosperm from another seed of the same species. For example, in the cross of Hordeum $\mathrm{x}$ secale the survival rate with the implantation technique was $30-40$ per cent as compared to one per cent with traditional method of embryo culture. This technique is termed as embryo-nurse endosperm transplant technique.

\section{Composition of the nutrient media/growth environment}

The most important aspect of the embryo culture is the selection of the right culture medium that would support progressive and orderly development of embryos excised at different stages of development. The requirement of culture medium depends on the types of embryo culture. They may be either post-germinal or pre-germinal. In the case of post-germinal embryo culture, embryos are cultured only to speed up the process after germination. This can be achieved with less complex medium or even with sucrose or glucose solution. In pre-germinal embryo culture, immature embryos are cultured to get plantlets, where the embryos require a complex nutrient medium. Refinement of nutrient medium for the culture of embryos includes modifications in the composition of mineral salts, organic nutrients and growth regulators, as for any other type of plant tissue cultures. The composition of the culture medium has to be formulated in such a way to suit the developmental phase of the embryo. There are two phases in embryo development i.e. heterotrophic phase in which the embryo draws its nutrients from the endosperm and the surrounding maternal tissues and autotrophic phase in which the embryo is metabolically capable of synthesizing substances required for growth. Addition of amino acids and vitamins, promoted the development of the embryo. Casein hydrolysate, an amino acid complex has been widely used as an additive to the embryo culture media. The natural plant extracts like coconut milk, tomato juice and extracts of banana produce higher recovery of growth and development of embryos.

Plant growth regulators generally play a small role in embryo culture. Exogenous auxins do not seem to be required for plant embryo growth in vitro and this observation supports reports that somatic embryo induction is inhibited by high concentrations of exogenous auxin in the medium and stimulated by low concentrations or in its absence. Cytokinins, when used as the sole hormone, are ineffective or only slightly promote young embryo growth. However, they promote growth and differentiation of embryos when they are combined with some auxins. Hormones should not be added to embryo culture media as they cause structural abnormalities. Auxins and cytokinins are not generally used for embryo culture unless callus induction is needed. Gibberellins sometimes stimulate precocious germination or are used to overcome dormancy.

Sucrose is primarily an energy source, although it also plays an important role in maintaining suitable osmotic potential of nutrient media. Mature embryos are usually grown on media with $2 \%$ to $3 \%$ sucrose, whereas immature embryos grow better at $8 \%$ to $12 \%$, which mimic the high osmotic potential within the young embryo sac. Generally, the younger the excised embryo, the higher the medium osmolarity required. 
Table.1 Resistance traits transferred to horticultural crops using embryo rescue technique (Sahijram et al., 2013)

\begin{tabular}{|l|l|l|}
\hline Sr. No. & Species crossed & Resistance trait/s \\
\hline 1 & Lycopersicon esculentum x L. peruvianum & Virus, fungi, nematodes \\
\hline 2 & Solanum melongena x S. khasianum & Brinjal fruit \& shoot borer \\
\hline 3 & Solanum tuberosum x S. etuberosum & Potato leaf-roll virus \\
\hline 4 & Brassica napus x B. oleracea var. acephala (kale) & Cabbage aphid \\
\hline 5 & A. esculentus A. moschatus & Yellow vein mosaic (YVM) \\
\hline 6 & Seedless lime x Acid lime & Citrus canker \\
\hline 7 & Sinapis arvensis x Raphanus sativus & Auxinic herbicide (Dicamba) \\
\hline
\end{tabular}

High osmolarity prevents precocious germination and keeps cells that are in a state of division from going into a state of elongation (Reinert et al., 1977).

Agar is the most commonly used agent to solidify culture media. Concentrations of $0.5 \%$ to $1.5 \%$ are generally used for embryo culture (Hu and Wang, 1986). High concentrations of agar may inhibit growth due to reduced water availability, quality of agar, or contaminating salts. Instead of agar using the vermiculite support system for small embryos of early maturing peach cultivars, obtained at fruit maturity, were cultured successfully and used as maternal parents in breeding programs (Pinto et al., 1994).

Light and temperature are two environmental factors that are of major concern in embryo culture. Light is known to influence the rates of cell division and ethylene evolution, which, in turn, may influence caulogenesis and rhizogenesis. Therefore, the duration and timing of light application play an important role in explant morphogenesis. It is usually recommended that cultures should be incubated in the dark until embryos or calluses appear for the first 1 to 2 weeks of culture and then transferred to light to allow chlorophyll formation. Isolated embryos frequently germinate in a wider temperature range than intact seeds. Some embryos require a cold treatment of $4^{\circ} \mathrm{C}$ to break dormancy. The growth of sweet cherry embryos was suitable when embryos were treated with 40 days and 60 days cold treatment $\left(4^{\circ} \mathrm{C}\right)$ on the immature and mature embryos respectively (Hajmansoor et al., 2009). The optimum temperature for growth of embryos depends on plant species, but normally a high range of 25 to $30 \mathrm{C}$ is used (Narayanaswami and Norstog, 1964). The growth conditions of the mother plant are also a consideration in embryo culture. The endosperm and the cotyledons will develop more if the mother plant is grown under wellcontrolled conditions; embryo growth will consequently be promoted.

\section{Various Techniques of Embryo Rescue}

There are broadly two types of embryo culture:

\section{Mature embryo culture}

It is the culture of mature embryos derived from ripe seeds. This type of culture is done when embryos do not survive in vivo or become dormant for long periods of time, or, is done to eliminate inhibition of seed germination.

\section{Immature embryo culture}

It is also known as embryo rescue, is the culture of immature embryos to rescue 
embryos from wide crosses, crosses involving seedless parent/s, or where fruit fall is heavy in early stages of embryo development. This is mainly used to avoid embryo abortion, with the purpose of producing a viable (hybrid) plant.

Wide hybridization, where individuals from two different species of the same genus or different genera are crossed, often leads to failure of the cross. Endosperm failure generally results in eventual starvation of the abnormal embryo (Raghavan, 1976). A successful protocol for immature embryo culture of Chinese jujube variety 'Lengbaiyu' has been developed by Ren et al., (2018).

Embryo culture is a valuable in vitro tool for breeding. It is most often used to rescue embryos from interspecific and intergeneric crosses and from embryos that do not fully develop naturally.

The method also can be used to rescue seedless triploid embryos, produce haploids, overcome seed dormancy and determine seed viability. It is useful in understanding embryo morphogenesis and precocious germination.

As research continues with this technique, new and valuable uses will be developed to assist the biotechnological breeding of plants.

\section{References}

Aguero C, Riquelme C. and Tizio R. 1995. Embryo Rescue from Seedless Grapevine (V. vinifera L.) Treated with Growth Retardant. Vitis, 34: 46-73.

Anderson N O, Ascher P D, Widmer R E \& Luby J J. 1990. Rapid generation cycling of chrysanthemum using laboratory seed development and embryo rescue techniques. Journal of the American Society for Horticultural Science, 115(2): 329-336.
Aroldo C and Noemi T Z. 2010. Embryo rescue and plant regeneration following interspecific crosses in the genus Hylocereus (Cactaceae). Euphytica, 174(1):73-82.

Assy-Bah B, Durand-Gasselin $\mathrm{T}$ and Pannetier C. 1987. In: Use of zygotic embryo culture to collect germplasm of coconut (Cocos nucifera L.). Plant Genetic Resources Newsletter, 71: 4-10.

Balla I \& Brozik S. 1993. Embryo culture of sweet cherry hybrids. In II International Cherry Symposium, pp. 385-386.

Benega-Garcia R, Cisneros A, Schneider B and Tel-Zur N. 2009. Gynogenesis in the vine cacti Hylocereus and Selenicereus (Cactaceae). Plant Cell Rep., 28:719-726.

Bentvelsen G C M, Stemkens H G W and Tjeertes P. 1990. Interspecific crosses in Pelargonium and the application of embryo rescue methods. In: Jong J. de (Ed.): Integration of in vitro techniques in ornamental plant breeding. Procs. of Symposium, Nov. 11-14.

Burgos L \& Ledbetter C A. 1993. Improved efficiency in apricot breeding: Effects of embryo development and nutrient media on in vitro germination and seedling establishment. Plant cell, Tissue and organ culture, 35(3): 217-222.

Cain D W, Emershad R L and Tarailo R E. 1983. In Ovule Embryo Culture and Seedling development of Seeded and Seedling Development of Seeded and Seedless Grapes (Vitis vinifera L.). Vitis, 22: 9-14.

Chadha K L and Sahijram L. 2000. Application of Biotechnology to Musa. In: Biotechnology in Horticultural and Plantation Crops. Eds. K.L. Chadha, P.N. Ravindran and Leela Sahijram, Malhotra Publishing House, New Delhi, India, pp. 232-247.

Cheng X, Chen S, Chen F, Deng Y, Fang W, Tang F \& Shao W. 2011. Creating novel chrysanthemum germplasm via 
interspecific hybridization and backcrossing. Euphytica, 177(1): 45-53.

Custers J B M. 1995. Embryo rescue in the genus Tulipa L.: Successful direct transfer of $\mathrm{T}$. kaufmanniana Regel germplasm into $T$. gesneriana $\mathrm{L}$. Euphytica, 82:253-261.

Doreswamy R and Sahijram L. 1993. Tissue Culture and Biotechnology. In: Advances in Horticulture Vol. 2 - Fruit Crops Part-2 (Eds: K.L. Chadha and O.P. Pareek), Malhotra Publishing House, New Delhi, India, pp 623-647.

Fassuliotus G. 1977. Self-fertilization of Cucumis metuliferus and its cross compatibility with Cucumis melo L. J. Amer. Soc. Hort. Sci. 102: 336-339.

Fathi H, Arzani K, Khalighi A and Ebadi A. 2002. The application of embryo culture in sweet cherry (Prunus avium L.) breeding. Abstract Book of the Third Iranian Horticultural Congress. 31 August -2 September, 355pp.

Hajmansoor S, Bihamta M R, Nabipour A, Mohammadi A, Pirseyedi S M \& Nikkhah H R. 2009. Genetic diversity in barley genotypes: I. Seed storage proteins (hordeins) and agronomic traits. Seed and Plant Improvement Journal, 25-1(4): 51 64.

$\mathrm{Hu} \mathrm{C}$ and Wang P. 1986. Embryo culture: Technique and application. In: Handbook of Plant Cell Culture, Vol. 4. Ed. D.A. Evans, W.R. Sharp, and P.V. Ammirato. Macmillan, New York. 43-96.

$\mathrm{Hu} \mathrm{C}$ and Wang P. 1986. Embryo culture: Technique and application. In: Handbook of Plant Cell Culture, Vol. 4. Ed. D.A. Evans, W.R. Sharp, and P.V. Ammirato. Macmillan, New York, 43-96.

Kasha K J \& Kao K N. 1970. High frequency haploid production in barley (Hordeum vulgare L.). Nature, 225 (5235): 874.

Kato J, Ishikawa R and Mii M. 2001. Different genomic combinations in intersection hybrids obtained from the crosses between Primula sieboldii (Section: Cortusoids) and P. obconica (Section: Obconiclisteri) by the embryo rescue technique. Theor. Appl. Genet., 102: 1129-1135.

Lu C \& Bridgen M P. 1997. Chromosome doubling and fertility study of Alstroemeria aurea $\times \quad$ A. caryophyllaea. Euphytica, 94(1): 75-81.

Mohapatra A \& Rout G R. 2005. Study of embryo rescue in floribunda rose. Plant cell, tissue and organ culture, 81(1): 113117.

Monnier M. 1984. Survival of young immature Capsella embryos cultured in vitro. J. Plant Physiol. 115:105-113.

Narayanaswami S and Norstog K, 1964. Plant embryo culture. Bot. Rev., 30: 587-628.

Nickell L G. 1951. Embryo culture of weeping crabapple. In Proceedings of the American Society for Horticultural Science, 57: 401-405.

North C and Wills A B.1969. Interspecific hybrids of Lilium lankongense Franchet produced by embryo culture. Euphytica, 18: 430-434.

Pinto A C, Rogers S M D \& Byrne D H. 1994. Growth of immature peach embryos in response to media, ovule support method, and ovule perforation. HortScience, 29(9): 10811083.

Prasad M B N V, Leela Sahijram and Rekha A. 1996. Role of embryo culture techniques in the improvement of seedless lime fruit quality. Nat'l. Symp. Hortl. Biotech., Bangalore, India, Oct. 2830.

Raghavan V, Embryo culture. 1980. In: Vasil, I. K., ed. Perspectives in plant cell and tissue culture. Int. Rev. Cytol. Suppl. 11B. New York: Academic Press, 209240.

Raghavan V.1976. Experimental Embryogenesis in Vascular Plants. Academic Press, London 
Reinert J, Bajaj Y P S, Nitsch C, Clapham D H \& Jensen C J. 1977. Haploids. In Applied and fundamental aspects of plant cell, tissue, and organ culture, Springer, Berlin, Heidelberg, pp. 249340.

Ren H, Du X, Li D, Zhao A, Wang Y, Xue \& Du, J. 2018. An efficient method for immature embryo rescue and plant regeneration from the Calli of Ziziphus jujuba 'Lengbaiyu'. The Journal of Horticultural Science and Biotechnology, 1-7.

Sahijram L, Soneji J R, Naren A \& Rao B M. 2013. Hybrid embryo rescue: a nonconventional breeding strategy in horticultural crops. Journal of Horticultural Science, 8(1): 1-20.

Sato S, Katoh N, Yoshida H, Iwai S, \& Hagimori M. 2000. Production of doubled haploid plants of carnation (Dianthus caryophyllus L.) by pseudo fertilized ovule culture. Scientia horticulturae, 83(3-4): 301-310.

Singh N V, Singh S K \& Singh A K. 2011. Standardization of embryo rescue technique and bio-hardening of grape hybrids (Vitis vinifera L.) using Arbuscular mycorrhizal fungi (AMF) under sub-tropical conditions. Vitis, 50(3), 115-118.

Sohrab S S, Bhattacharya P S, Rana D, Kamal M A \& Pande M K. 2015. Development of interspecific Solanum lycopersicum and screening for Tospovirus resistance. Saudi journal of biological sciences, 22(6): 730-738.

Spiegel-roy P, Sahar N, Baron J and Levi U. 1985. In vitro culture and plant formation from grape cultivars with abortive ovules and seeds. J. Amer. Soc. Hort. Sci., 110 (1): 109-112.

Tamaki M, Urasaki N, Nakamura I, Motomura $\mathrm{K}$ and Adaniya $\mathrm{S}$. 2011. Shortening the breeding cycle of papaya (Carica papaya L.) by culturing embryos treated with ethrel. Plant Cell, Tissue and Organ Culture (PCTOC), 106(2): 225-233.

Tom Eeckhaut, Ellen De Keyser, Johan Van Huylenbroeck, Jan de Riek and Erik Van Bockstaele. 2007. Application of embryo rescue after interspecific crosses in the genus Rhododendron. Pl. Cell Tiss. Org. Cult., 89:29-35.

Tukey H B \& Carlson R F. 1945. Breaking the dormancy of peach seed by treatment with thiourea. Plant physiology, 20(4): 505.

Utami E S W, Hariyanto S \& Manuhara Y S W. 2017. In vitro propagation of the endangered medicinal orchid, Dendrobium lasianthera JJ Sm through mature seed culture. Asian Pacific Journal of Tropical Biomedicine, 7(5): 406-410.

Vidhanaarachchi V R M, Suranjith W C \& Gunathilake T R. 2016. Effect of genotype, embryo maturity and culture medium on in vitro embryo germination of Sri Lankan coconut (Cocos nucifera L.) varieties. Journal of the National Science Foundation of Sri Lanka, 44(3): 273-278.

Zenkteler E \& Zenkteler M. 2016. Development of haploid embryos and plants of Lactuca sativa induced by distant pollination with Helianthus annuus and $H$. tuberosus. Euphytica, 208(3): 439-451.

\section{How to cite this article:}

Poonam Kumari, Thaneshwari and Rahul. 2018. Embryo Rescue in Horticultural Crops. Int.J.Curr.Microbiol.App.Sci. 7(06): 3350-3358. doi: https://doi.org/10.20546/ijcmas.2018.706.393 